\title{
Body Image Satisfaction and Life Satisfaction in HIV/AIDS Patients
}

\author{
Pankaj Jain $^{1 *}$, Gyanesh Kumar Tiwari ${ }^{2}$
}

\section{ABSTRACT}

The present study attempted to elucidate the nature and extent of relationship between body satisfaction and life satisfaction of the diagnosed Human Immune Virus/Acquired Immuno Deficiency Syndrome ((HIV/AIDS) patients and the individuals with no known chronic physical and/or mental health illnesses. Eighty participants encompassing forty diagnosed HIV/AIDS patients comprising twenty seven males $(\mathrm{M}=35.63$, $\mathrm{SD}=4.58)$ and thirteen females $(\mathrm{M}=$ 33.69 , SD = 3.57) and forty postgraduate students containing twenty eight male $(\mathrm{M}=28.00$, SD $=4.78)$ and twelve females $(\mathrm{M}=24.17, \mathrm{SD}=5.99)$ took part in the present study. The body image satisfaction and life satisfaction were assessed with the help of Body Esteem Scale for Adolescents and Adults (Mendelson, Mendelson, \& White, 2001) and Life Satisfaction Scale (Alam \& Shrivastava, 2001), respectively. The results of the study demonstrated that the participants suffering from HIV/AIDS had lower mean body image satisfaction score $(\mathrm{M}=$ 48.78, $\mathrm{SD}=6.61)$ as compared to the normal participants $(\mathrm{M}=76.90$, SD $=5.12)$. Likewise, the life satisfaction scores of HIV/AIDS showed lesser mean score $(\mathrm{M}=38.50$, $\mathrm{SD}=4.88)$ as compared to the normal healthy $(\mathrm{M}=44.25$, $\mathrm{SD}=3.33)$. The current theoretical and empirical findings related to body image satisfaction, life satisfaction and chronic physical illnesses have been used to discuss the results of the present study. The findings of the study would have noteworthy theoretical and practical implications for researchers, clinicians, government health policy makers, health professionals and administrators.

Keywords: Body image, body image satisfaction, Life satisfaction, Chronic disease, HIV/AIDS.

Body image satisfaction and life satisfaction are closely associated with the nature and status of physical and mental health of the individuals. Body image constitutes one of the interesting topics of research among the researchers even to those with inter-disciplinary interests. The individuals differ in their perceptions of their own body and their perceptions may not fit to the societal standards and expectations. An individual's perception of body image impacts his psychological functioning, well-being and self-esteem (Tiwari, 2014; Tiwari \& Kumar, 2015).

\footnotetext{
${ }^{1}$ (Research Scholar, Department of Psychology, School of Humanities \& Social Sciences, Doctor Harisingh Gour Vishwavidyalaya, Sagar, MP., India

${ }^{2}$ Assistant Professor, Department of Psychology, School of Humanities \& Social Sciences, Doctor Harisingh Gour Vishwavidyalaya, Sagar, MP., India

*Responding Author

(C) 2016 I P Jain, G Tiwari; licensee IJIP. This is an Open Access Research distributed under the terms of the Creative Commons Attribution License (http://creativecommons.org/licenses/by/2.0), which permits unrestricted use, distribution, and reproduction in any Medium, provided the original work is properly cited.
} 


\section{Body Image Satisfaction and Life Satisfaction in HIV/AIDS Patients}

Body image is a multidimensional construct representing cognitive, affective and behavioural responses to an individual's own physical and psychological attributes and comprised of body image satisfaction or dissatisfaction with one's physical attributes and experience of discrete emotions (Muth \& Cash, 1997). The term body image refers to the extent to which individuals perceive the facts pertaining to their body and body parts which may result either in satisfaction and dissatisfaction.

Body image plays key role in the development of self-concept as it serves as an important base for self-evaluation and evaluation by others (Thompson, Heinberg, Altabe, \& Tantleff-Dunn, 1999). Physical and mental health conditions, mass media, individual psychological factors, socio-economic status, genetics and health behaviours are some of the important antecedents which shape the body image perceptions of the individual (Burroes, 2013; Tiwari, 2015). It has been reported that the obese individuals are more prone to have lowered body satisfaction than those who are normal. Body weight has been reported to be the most reliable factor predicting body image regardless of gender or ethnicity (Xanthopoulos, Borradaile, Hayes, Sherman, Vander Veur, Grundy, \& Foster, 2011). Beliefs regarding some sort of perfect body images, tendency to compare themselves to others and sense of insecurity are some of the additional psychological correlates of body satisfaction. An association between negative body image and depression has been found for both male (Cohane, \& Pope, 2001) and female (Pesa, Syre, \& Jones, 2000) adolescents with the females experiencing depression more than their male counterparts (Sujoldzić, \& De Lucia, 2007). The individuals having a prior history of social

phobia (Izgiç, Akyüz, Dogcaron \& Kugcaron, 2004), internalization of thin body image (Cafri, Yamamiya, Brannick \& Thompson, 2005) and extreme social comparisons (Myers \& Crowther, 2009) were more prone to experience lower body image satisfaction. A variety of consequences have been associated with one's level of body satisfaction. School absenteeism (Yanover \& Thompson, 2008), lower self-forgiveness and life satisfaction (Mudgal \& Tiwari, 2015) sense of muscularity, self-confidence/self-esteem (Tiwari, 2014) and mental health (Furnham \& Calnan, 1998), achievements in life (McCabe, Ricciardelli, \& Finemore, 2002), eating behavior and addictions (Drewnowski \& Yee, 1987) have been reported to be correlated with one's body satisfaction.

Many physical health conditions have also been associated with body image dissatisfaction and lowered life satisfaction (Mudgal \& Tiwari, 2015). The higher levels of psychological distress have been reported by some people living with skin conditions. The Psychological difficulties commonly reported are anxiety, depression, lowered self-esteem (Tiwari, 2014), and feeling of shame, as well as body image concerns. Lipodystrophy (fat loss in arms, legs, face) or gain (abdomen, breasts) that is frequently secondary to HAART HIV-infected individuals with lipodystrophy are more likely than those without lipodystrophy to experience body image dissatisfaction (Burgoyne, Collins, Wagner, Abbey, Halman, Nur \& Walmsley, 2005; Guaraldi et al., 2008; Marin, Sabogal, Marin \& Otero-Sabogal, 1987). 
Cancer and cancer treatments can significantly change appearance and body integrity, particularly in some cancers. For some people in distress associated with cancer centers on appearance-related changes that may act as persistent reminder of the disease. Such distress can trigger preexisting vulnerability to psychological disorders and adjustment problems (Rocco, Orbitello, Perini, Pera, Ciano \& Balestrieri, 2005). There is now established literature that reveals that breast, cervical, and genital cancer can impact negatively on women's body image. De Beradis and colleagues (2005) found that alexithymic women with premenstrual dysphoric disorder (PDD) exhibited significantly greater body dissatisfaction than nonalexithymics. Alexithymia is a characterized by the inability to express one's emotion and feeling in words.

The review of the literature demonstrated that physical and mental health conditions significantly affect body image satisfaction and life satisfaction of the individuals. The individuals suffering from HIV/AIDS undergo and face many undesirable physical and psychological changes which affect their direction and level of body image satisfaction ultimately resulting into quality of life and life satisfaction. The review also evinces that there is a dearth of studies showing the impacts of HIV/AIDS on body image satisfaction and life satisfaction of the individuals. This is the case with both Indian as well as Western and American socio-cultural milieu. It is also to be argued that the physical and psychological harms caused by the sufferings of HIV/AIDS may significantly take different forms as compared to other ill physical health conditions which have been inadequately covered in the scientific endeavors of the researchers. It can be argued that the nature and extent of the harm to the individuals' body image satisfaction and life satisfaction in HIV/AIDS in comparison to other physical illnesses would be exhibited in dissimilar manner. The present study has attempted to explore the nature and interrelationships between the body satisfaction and life satisfaction of the clinical (HIV/AIDS patients) and non-clinical (normal healthy) participants.

\section{Hypotheses}

The review of the existing literature paved the way for the formulation of the following hypotheses for the present study:

1. The mean body image satisfaction score of the normal participants would be higher as compared to the mean body image satisfaction score of the participants having HIV/AIDS.

2. The mean life satisfaction score of the normal participants would also be higher with that of the mean life satisfaction score of the participants suffering from HIV/AIDS.

\section{METHOD}

\section{Participants}

Forty diagnosed HIV/AIDS patients registered in Antiretroviral Therapy (ART) Center Bundelkhand Medical College, Sagar, M. P. comprising twenty seven males $(\mathrm{M}=35.63$, SD = 4.58) and thirteen females $(\mathrm{M}=33.69, \mathrm{SD}=3.57)$ and forty postgraduate students from Doctor Harisingh Gour University Sagar, Madhya Pradesh, India comprising twenty eight male $(\mathrm{M}=$ 
28.00, $\mathrm{SD}=4.78)$ and twelve females $(\mathrm{M}=24.17, \mathrm{SD}=5.99)$ constituted the sample for the present study whose age ranged from 19 to 42 years. They belonged to different socioeconomic backgrounds predominantly lower middle class. The educational qualifications spanned from high school to post-graduation in multiple disciplines.

\section{Tools}

To assess the degree to which participants are satisfied with their bodies, the Body Esteem Scale for Adolescents and Adults (Mendelson et al., 2001) was used. The scale was originally in English which was translated first in Hindi followed by retranslation in English. The scale consists of 21 items tapping participants' estimation of their weight (e.g., "I am preoccupied with trying to change my body weight"), the degree to which they attribute positive outcomes from their weight (e.g., "My looks help me to attract friendship"), and their appearance (e.g., "I like what I see when I look in the mirror"). The word 'date' of the original scale was replaced with the word 'attract', nearest and appropriate in meaning, while translating the scale in Hindi as the date is not common and popular in Indian socio-cultural setting. The scale consists of three subscales viz., appearance, weight, and attribution. The Appearance subscale measures one's general feelings about one's appearance. It has Chronbach's alpha of .92 indicating higher internal consistency. The Weight subscale measures weight satisfaction. It also demonstrates high internal consistency with a Chronbach's value of .94. The Attribution subscale measures one's perceptions about others' evaluation of one's body and appearance and has a Chronbach's alpha value of .81. After reverse scoring of the appropriate items, the participants' responses were averaged across items. Higher scores on the subscales indicated more positive body esteem and satisfaction.

To measure life satisfaction of the participants, The Life Satisfaction Scale (Alam at el., 2001) was used. The scale contained 60 items with 'Yes' and 'No' options each. The items of the scale were associated with six areas (Health, Personnel Economic, Marital, Social and occupational) of human functioning. Yes response indicated satisfaction, whereas No signified dissatisfaction with life. Every 'Yes' response was assigned 1 whereas 'No' was scored as 0 . The sum of the scores was obtained for the entire scale. The test-retest reliability of the scale was found to be .84 .

\section{Procedure}

After having been debriefed about the basic goals of the study, the participants gave their written consent to participate in the study. It was made clear to them that their participation in the study was voluntary and they could withdraw themselves from the study at any point of time. The participants were made comfortable and the researchers established rapport with them followed by oral instructions about the methods of answering to the alternatives of the items of the scales. Then the participants were given a set of the scales. Each item of the Body Esteem Scale for Adolescents and Adults contained 1, 2, 3, 4, and 5 on the right margin which signified Never, Seldom, Sometimes, Often and Always, respectively. The participants had to put the mark of 
right $(\sqrt{ })$ on the applicable number denoting their closest meaning/feeling for the contents of each item. 8 items (4, 7, 9, 10, 12, 16, 17 \& 19) were reversely scored (5, 4, 3, 2 \& 1) while the rest were scored rightward (1, 2, 3, 4 \& 5). The items of the Life Satisfaction Scale contained 2 options (Yes/No). The participants had to put the symbol of right $(\sqrt{ })$ either on Yes or No as per their agreements with content/s inherent in each item. The mean, Standard (SD) and t-test were carried out on the collected data of the study the details of which have been presented in the following sections.

\section{RESULTS}

The results of the study indicated that HIV/AIDS patients emitted lower mean body image satisfaction score $(\mathrm{M}=48.78, \mathrm{SD}=6.61)$ as compared to the normal participants $(\mathrm{M}=76.90$, SD $=5.12)$. Likewise, their mean life satisfaction was also lower $(\mathrm{M}=38.50, \mathrm{SD}=4.88)$ in the face of the normal $(\mathrm{M}=44.25$, $\mathrm{SD}=3.33)$ participants.

Table 1: Mean body image satisfaction and life satisfaction scores of HIV/AIDS and normal participants

\begin{tabular}{|l|l|l|l|l|l|}
\hline S. No. & Participants & Measures & Mean & SD & N \\
\hline \multirow{2}{*}{1.} & \multirow{2}{*}{ HIV/AIDS } & Body satisfaction & 48.78 & 6.61 & 40 \\
\cline { 3 - 6 } & & Life satisfaction & 38.50 & 4.88 & 40 \\
\hline \multirow{2}{*}{2.} & \multirow{2}{*}{ Normal } & Body satisfaction & 76.90 & 5.12 & 40 \\
\cline { 3 - 6 } & & Life satisfaction & 44.25 & 3.33 & 40 \\
\hline
\end{tabular}

The mean scores of body image satisfaction and life satisfaction of the clinical and non-clinical participants were compared by computing t-test. The analyses showed that the mean scores of body image satisfaction of the participants with HIV/AIDS and normal healthy differed significantly $(\mathrm{t}=5.23, \mathrm{df}=39, p=.001)$.

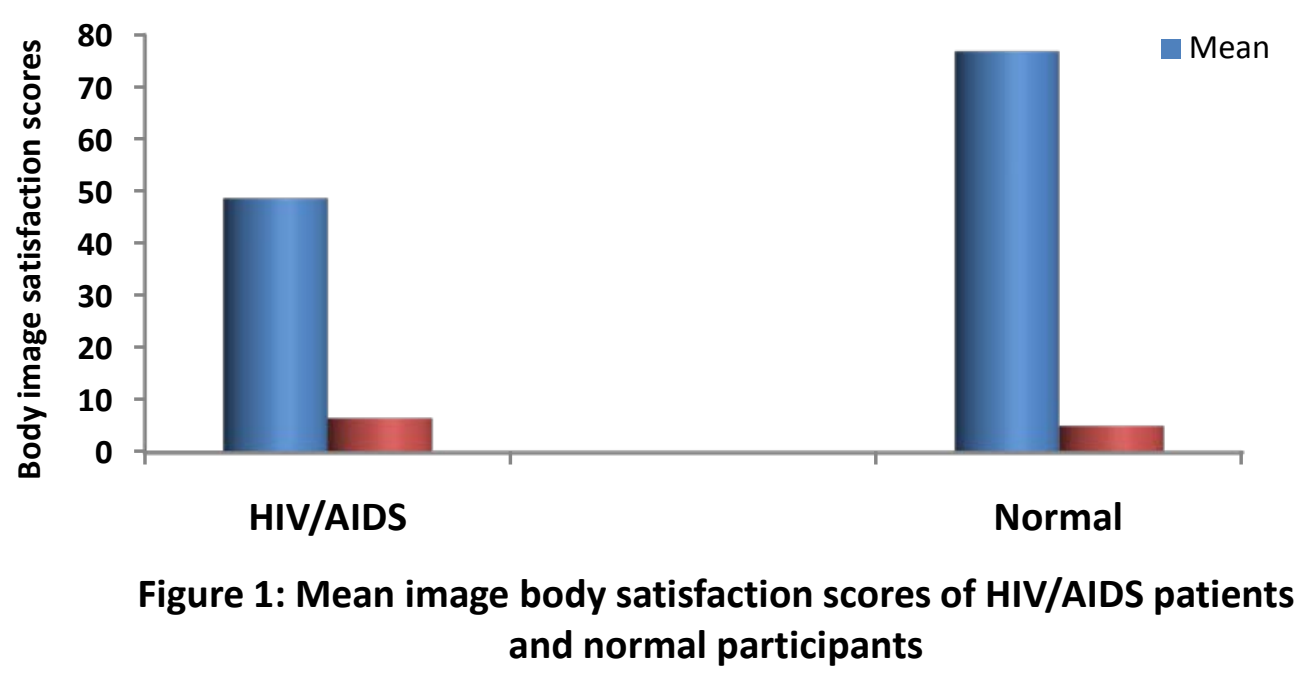


Similarly, the mean scores of life satisfaction of the two groups also demonstrated statistically significant difference $(\mathrm{t}=6.19, \mathrm{df}=39, p=.001)$. These results have been displayed in Table 1 and Figures 1 and 2.

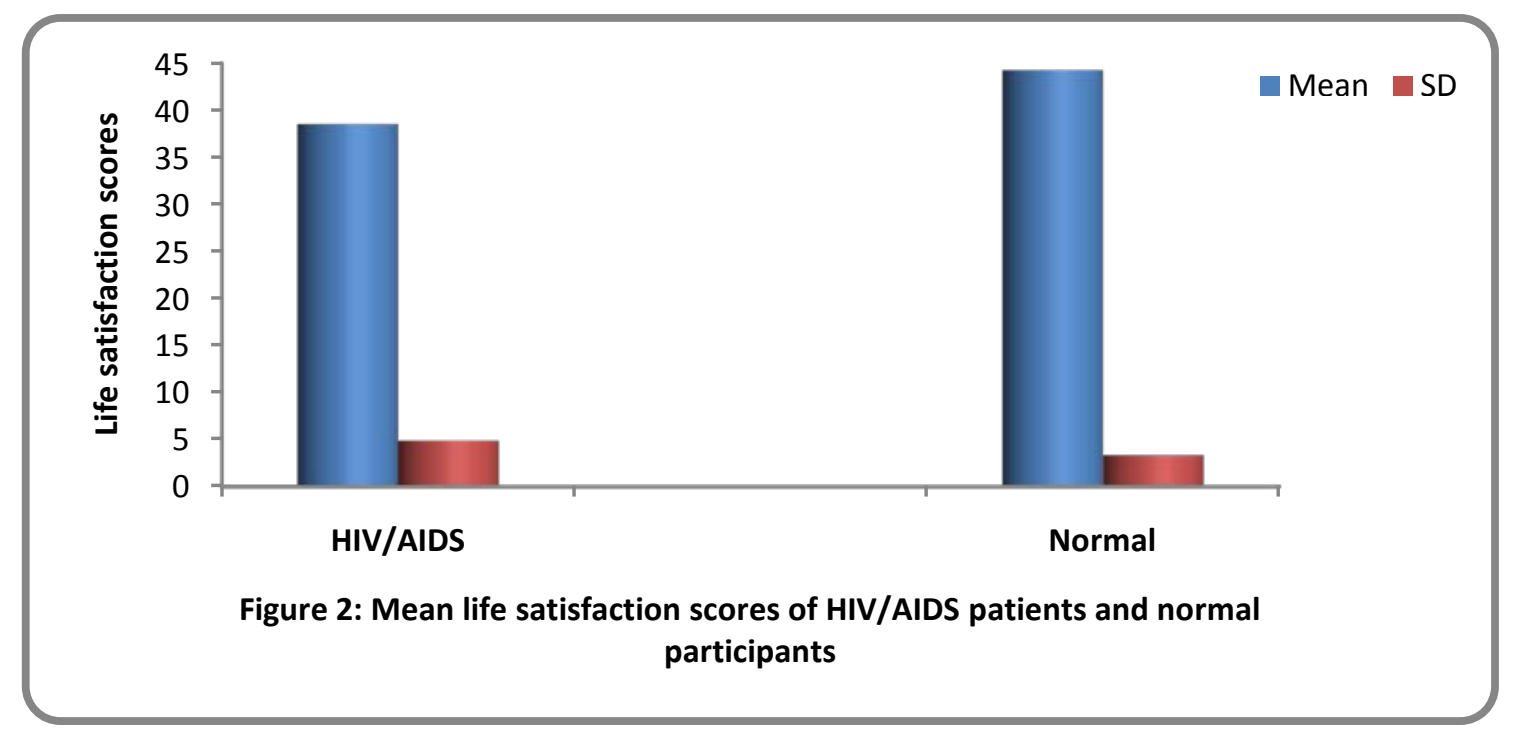

\section{DISCUSSION}

The results of the present study demonstrated that chronic disease of HIV/AIDS significantly shaped the body image satisfaction and life satisfaction of the participants. The clinical patients emitted lower mean scores on both the measures as compared to the normal healthy which approved Hypotheses 1 and 2. There were multiple sources of body image satisfaction pooled in the scale and these sources actually supply regular information about once body image. The HIV/AIDS patients witness sharp and sudden deterioration in their shape, size and functioning of their body, their body image satisfaction might have surely gone down. These findings were supported by previous studies pertaining to body image satisfaction (Kelly Langdon \& Serpell, 2009; Yang, Lee, \& Kim, 2015). The present study demonstrated that the participants living with HIV/AIDS had lower body image satisfaction and life satisfaction as compared to their normal counterparts.

According to the findings of research on HIV/AIDS patients, the therapeutic method of HAART used to treat the symptoms of AIDS has a significant negative impact on individuals' body image, life satisfaction, and mood. The HIV patients reported feeling "unclean" and "contaminated", and the act of taking ART medications as a daily reminder of the viral infection. HIV/AIDS has a significant impact on the feeling of body infectivity. The antecedents of body image of people living with HIV/AIDS include "HIV infection \& AIDS diagnosis" and "Existing body perception", while the consequences of body image of People living with HIV/AIDS include "negative health consequences" and, "lower life satisfaction” (Yang, Lee, \& Kim, 2015). A diagnosis of AIDS is significantly related to poorer quality of body image and lowered self- 
forgiveness and life satisfaction (Mudgal \& Tiwari, 2015) as well as non-adaptive use of emotion regulation strategies (Tiwari, 2015). Thus, the label of HIV/AIDS, independent of other factors, has the power to detrimentally change the body image of the person. Body image and HAARTassociated body changes have been linked to physical discomfort, worries about disclosure, social isolation, suboptimal, adherence, low satisfaction of life and mental health problems. The changes in body shape and composition that are associated with lipodystrophy which impacts body image. HIV-infected individuals with HAART-related lipodystrophy are significantly more likely than HIV-infected individuals without HAART-related lipodystrophy to report body image dissatisfaction. Lipodystropy is associated with diminished self-esteem and depression, fear of stigmatization, problems with dressing and social isolation. A person with low body esteem would be more adversely affected than someone with higher body esteem scores; thus the effect that the people living with HIV/AIDS have poorer body image and life satisfaction due to body image dissatisfaction (Yang, Lee, \& Kim, 2015). The results of the study can be interpreted in terms of the Contingencies of Self-Worth Theory which proposes that satisfaction with body has important impacts on global self-esteem (Crocker, Luhtanen, Cooper, \& Bouvrette, 2003). Thus body dissatisfaction results into lowered self-esteem consequent of which the level of life satisfaction of the participants goes down also. This may be the case with the HIV/AIDS participants of the present study who demonstrated both decreased body satisfaction and body satisfaction as compared to the normal participants.

\section{CONCLUSIONS}

The results of the present study evinced that the HIV/AIDS patients showed lowered body image satisfaction and life satisfaction as compared to normal healthy participants. The disease shaped their body image satisfaction and life satisfaction. The results of the study demonstrated that there are much remains to be learned about the perception of body image and life satisfaction of the persons suffering from chronic diseases. HIV/AIDS is an incurable disease so that people with this disease have stigma, which leads to deterioration of the sense of their body image. Furthermore, they lose their social support and reminded of their illness, so that they remain preoccupied with their negative body image which results into decreased satisfaction with their lives.

\section{Suggestions for Future Research}

The present study has been marred by certain limitations also. The small sample, short age range, small cultural and ethnic affiliations of the participants and limited number of variables constitute some the limitations of the study. These limitations restrict the generalizability of the results. Future research is needed to work on diversified sample adopting qualitative methods with adequate number of variables. Cross-cultural study will be fruitful to make the results more useful and insightful. The results and conclusions of the study have important implications for future researchers, planners, policy makers and health professionals who are associated with the extending services for the persons living with HIV/AIDS. 


\section{Acknowledgement}

The authors acknowledge the contributions of Dr. Abhay Tirkey, Nodal Officer, ART Center Bundelkhand Medical College, Sagar, M .P., Mr. Anupam Bohre, Senior Counsellor and National AIDS Control Organization (NACO), India without whose permission and support the present study could not have been possible. The cooperation and help of Dr. Shikha Agrawal, Medical Officer, is also worth mentioning who provided us with appropriate knowledge of the disease and treatment. We appreciate the Department of Psychology, Doctor Harisingh Gour University, Sagar, M. P. for permitting and encouraging us to conduct the study. We are also thankful to Miss Sujata Mudgal, Research Scholar, Department of Psychology, School of Humanities \& Social Sciences, Doctor Harisingh Gour University, Sagar, M. P. for helping us in data collection and keeping the record.

\section{REFERENCES}

Alam, Q. G., \& Srivastava, R. (2001). Life satisfaction scale. National Psychological Corporation, Agra, India.

Burgoyne, R., Collins, E., Wagner, C., Abbey, S., Halman, M., Nur, M., \& Walmsley, S. (2005). The relationship between lipodystrophy-associated body changes and measures of quality of life and mental health for HIV-positive adults, Quality of Life Research, 14 (4), 981990.

Burroes, N. (2013). Body image-A rapid evidence assessment of the literature. A project on behalf of the Government Equalities Office.

Cafri, G., Yamamiya, Y., Brannick, M., \& Thompson, J. K. (2005). The influence of sociocultural factors on body image: A meta-analysis. Clinical Psychology: Science and Practice, 12 (4), 421-433.

Cohane, G., \& Pope, H. (2001). Body image in boys: a review of the literature. The International Journal of Eating Disorders, 29(4), 373-379.

Crocker, J., Luhtanen, R. K., Cooper, M. L., \& Bouvrette, A. (2003). Contingencies of self-worth in college students: Theory and measurement. Journal of Personality and Social Psychology, 85, 894-908.

De Berardis, D., Campanella, D., Gambi, F., Sepede, G., Carano, A., Pelusi, L., et al. (2005). Alexithymia and body image disturbances in women with premenstrual dysphoric disorder. Journal of Psychosomatic Obstetrics and Gyanaecology, 26, 257-264.

Drewnowski, A., \& Yee, D. K. (1987). Men and body image: Are males satisfied with their body weight? Psychology Med, 40, 626-634.

Furnham, A., \& Calnan, A. (1998). Eating disturbance, self-esteem, reasons for exercising and body weight dissatisfaction in adolescent males. European Eating Disorders Review, 6, 58-72.

Guaraldi, G., Orlando, G., Murri, R., Vandelli, M., De Paola, M., Beghetto, B., Nardini, G., Ciaffi, S., Vichi, F., \& Esposito, Wu AW. (2006). Quality of life and body image in the assessment of psychological impact of lipodystrophy: validation of the Italian version of assessment of body change and distress questionnaire, Quality of Life Research, 15 (1), 173-178. 


\section{Body Image Satisfaction and Life Satisfaction in HIV/AIDS Patients}

Izgiç, F., Akyüz, G., Do\&gcaron;n, O., \& Ku\&gcaron;u, N. (2004). Social Phobia Among University Students and Its Relation to Self-Esteem and Body Image. Canadian Journal of Psychiatry, 49 (9), 630-634.

Kelly J. S., Langdon D., \& Serpell L. (2009). “The Phenomenology of body image in men living with HIV" Journal of AIDS Care Psychological and Socio-medical Aspects of AIDS/HIV, Vol. 21 (12), 1560_1567 ISSN: 0954-0121. DOI: 10.1080/09540120902923014

Marin, G., Sabogal, F., Marin, B. V., \& Otero-Sabogal, R. (1987). Development of a short acculturation scale for Hispanics. Hispanic Journal of Behavioral Sciences, 9(2), 183205.

McCabe, M. P., Ricciardelli, L. A., \& Finemore, J. (2002). The role of puberty, media and popularity with peers on strategies to increase weight, decrease weight and increase muscle tone among adolescent boys and girls. Journal of Psychosomatic Research, 52, 145-154.

Mendelson B. K., Mendelson, M. J., \& White, D. R. (2001). Body Esteem scale for adolescents and adults. Journal of Personality Assessment, 76 (1), 90-106.

Mudgal, S., \& Tiwari, G. K. (2015). Self-forgiveness and life satisfaction in people living with HIV/AIDS. The International Journal of Indian Psychology, Volume 3, Issue 1, No. 10, 101-108. DIP: C03175V3I12015

Muth, J. L., \& Cash, T. F. (1997). Body-image attitudes: What difference does gender make? Journal of Applied Social Psychology, 27, 1438-1452.

Myers, T., \& Crowther, J. (2009). Social comparison as a predictor of body dissatisfaction: A meta-analytic review. Journal Of Abnormal Psychology, 118(4), 683-698.

Pesa, J., Syre, T., \& Jones, E. (2000). Psychosocial differences associated with body weight among female adolescents: the importance of body image. The Journal Of Adolescent Health: Official Publication Of The Society For Adolescent Medicine, 26(5), 330-337.

Rocco, P.L., Orbitello, B., Perini, L., Pera, V., Ciano, R. P., \& Balestrieri, M. (2005). Effects of pregnancy on eating attitudes and disorders: a prospective study. Journal of Psychosomatic Research, 59(3), 175-179.

Sujoldzić, A., \& De Lucia, A. (2007). A cross-cultural study of adolescents--BMI, body image and psychological well-being. Collegium Antropologicum, 31(1), 123-130.

Thompson, J. K., Heinberg, L. J., Altabe, M., \& Tantleff-Dunn, S. (1999). Exacting beauty: Theory, assessment and treatment of body image disturbance. Washington, DC: American Psychological Association.

Tiwari, G. K., \& Kumar, S. (2015). Psychology and body image: A review. SHODH PRERAK, $5,1-9$.

Tiwari, G. K. (2014). Body image satisfaction enhances self-esteem. VAICHARIKI, 4 (4), 7-11.

Tiwari, G. K. (2015). Chronic physical illness affects emotion regulation process: A case of HIV/AIDS. The International Journal of Indian Psychology, Volume 3, Issue 1, No. 8, 158-167. DIP: C03143V3I12015 


\section{Body Image Satisfaction and Life Satisfaction in HIV/AIDS Patients}

Xanthopoulos, M., Borradaile, K., Hayes, S., Sherman, S., Vander Veur, S., Grundy, K., \& Foster, G. (2011). The impact of weight, sex, and race/ethnicity on body dissatisfaction among urban children. Body Image, 8(4), 385-389.

Yang, H. J., Lee, H. K., \& Kim, M, (2015). "The concept analysis of body image of people living with HIV/AIDS” International Journal of Bio-Science and Bio-Technology, Vol. 7 (4), 315-334. DOI:10.14257

Yanover, T., \& Thompson, J. K. (2008). Eating problems, body image disturbances, and academic achievement: Preliminary evaluation of the eating and body image disturbances academic interference scale. International Journal of Eating Disorders, 41(2). 184-187. 